Revista Universo Contábil, ISSN 1809-3337
Blumenau, v. 16, n. 2, p. 50-66, abr./jun., 2020

\title{
DESEMPENHO DOS MUNICIPIOS BRASILEIROS: UMA ANÁLISE GERENCIAL DA REALIDADE ECONÔMICA E FISCAL POR MEIO DO EFEITO FLYPAPER
}

\section{PERFORMANCE OF BRAZILIAN MUNICIPALITIES: A MANAGEMENT ANALYSIS OF THE ECONOMIC AND FISCAL REALITY THROUGH THE FLYPAPER EFFECT}

\section{DESEMPEÑO DE MUNICIPIOS BRASILEÑOS: UN ANÁLISIS DE GESTIÓN DE LA REALIDAD ECONÓMICA Y FISCAL A TRAVÉS DEL EFECTO DE FLYPAPER}

Recebido em: 10-04-2020

Avaliado em: 22-07-2020

Reformulado em: 30-07-2020

Aceito para publicação em: 21-08-2020

Publicado em: 26-04-2021

Editor Responsável: Roberto Carlos Klann

\author{
Rodrigo Noleto Paz ${ }^{1}$ \\ André Luiz Marques Serrano ${ }^{2}$ \\ Lucas Oliveira Gomes Ferreira ${ }^{3}$
}

\section{RESUMO}

A pesquisa testou a influência da capacidade gerencial econômica sobre o desempenho dos municípios brasileiros, avaliando o efeito flypaper, fenômeno que avalia o descompasso na execução orçamentária e financeira dos entes federativos. Os governantes criam distorções sobre a realidade fiscal nos contribuintes, dificultando a percepção sobre o preço dos serviços públicos, por meio de mecanismos como utilização de transferências governamentais para aumento de gastos, ao invés de redução de impostos. A pesquisa objetiva analisar as evidências a partir dos estudos de Araújo (2014) e Araújo e Siqueira (2016), por meio da utilização de dados em painel. Foram definidas as variáveis que traduzem a execução orçamentária e financeira (receita tributária, despesa corrente, transferências correntes, população municipal e PIB), dados referentes a 5.570 municípios em um período de quatorze anos (2005 a 2018). Os resultados da aplicação em dados em painel com efeitos fixos revelaram que o efeito não é aplicável no período avaliado, ou seja, os testes econométricos permitiram verificar que a realidade econômica e fiscal dos municípios brasileiros no período não se alinha aos preceitos do efeito flypaper, visto que a elasticidade gasto/repasse não é superior à unidade.

Palavras-chave: Desempenho de Organizações Públicas. Municípios Brasileiros. Efeito Flypaper.

\footnotetext{
${ }^{1}$ Especialista em Controle Externo na Universidade de Brasília (UnB); E-mail: andrelms.unb@gmail.com

${ }^{2}$ Professor do Departamento de Engenharia de Produção da Universidade de Brasília (UnB); E-mail: andrelms@unb.br

3 Professor do Departamento de Ciências Contábeis e Atuariais da Universidade de Brasília (UnB); E-mail: lucasoliveira@unb.br
} 


\begin{abstract}
The research tested the influence of economic management capacity on the Brazilian municipalities' performance, evaluating the flypaper effect, a phenomenon that assesses the gap in the budgetary and financial execution of the federal entities. Thus, the government creates distortions about the taxpayers' tax reality, making it difficult to perceive the price of public services through mechanisms such as the use of government transfers to increase expenses instead of reducing taxes. The research aims to analyze the evidence from the studies of Araújo (2014) and Araújo and Siqueira (2016) by panel data. The budgetary and financial variables were defined (tax revenue, current expenditure, current transfers, municipal population, and GDP), and the data of 5,570 municipalities over fourteen years (2005 to 2018). The results of the fixed effects panel data evidenced the effect is not applicable in the analyzed period, as the econometric tests allowed to verify that the economic and fiscal reality of the Brazilian municipalities in the period is not in line with the concept of the flypaper effect since the elasticity expenses/grants is not higher than the unit.
\end{abstract}

Keywords: Performance of Public Organizations. Brazilian Municipalities. Flypaper Effect.

\title{
RESUMEN
}

La investigación probó la influencia de la capacidad de gestión económica en el desempeño de los municipios brasileños, evaluando el efecto flypaper, un fenómeno que evalúa la brecha en la ejecución presupuestaria y financiera de las entidades federales. Por lo tanto, el gobierno crea distorsiones sobre la realidad fiscal en los contribuyentes, lo que dificulta la percepción del precio de los servicios públicos, a través de mecanismos como el uso de transferencias gubernamentales para aumentar los gastos en lugar de reducir los impuestos. La investigación tiene como objetivo analizar la evidencia de los estudios de Araújo (2014) y Araújo y Siqueira (2016) mediante el uso de datos de panel. Se definieron las variables que reflejan la ejecución presupuestaria y financiera (ingresos fiscales, gastos corrientes, transferencias corrientes, población municipal y PIB), datos que se refieren a 5.570 municipios durante un período de catorce años (2005 a 2018). Los resultados de la aplicación en datos de panel con efectos fijos revelaron que el efecto no es aplicable en el período evaluado, es decir, las pruebas econométricas permitieron verificar que la realidad económica y fiscal de los municipios brasileños en el período bajo examen no se alinea con los preceptos de la efecto flypaper, ya que la elasticidad gastada / transmitida no es mayor que la unidad.

Palabras clave: Desempeño de Organizaciones Públicas. Municipios Brasileños. Efecto Flypaper.

\section{INTRODUÇÃO}

Ao longo dos últimos exercícios financeiros, entes subnacionais vêm relegando para segundo plano questões que envolvem o planejamento das ações governamentais, o que traz desequilíbrios na alocação de recursos e, por conseguinte, na execução dos gastos públicos. Reflexo disso são as crises fiscais, trivialmente observadas no âmbito dos estados e municípios brasileiros, em que o ritmo de execução da despesa se encontra, em muitos casos, superior ao da receita. Nessa perspectiva, a teoria do federalismo fiscal surge como fator importante nesse processo de alocação de recursos entre os diversos entes da federação. Essa interação estimula a própria concorrência entre os entes, ao mesmo tempo em que tende a aumentar a eficiência na provisão de bens e serviços públicos, comparativamente à ofertada por uma administração rígida e centralizada (Araújo \& Siqueira, 2016).

As transferências intergovernamentais decorrentes do pacto federativo podem ensejar aumento nos gastos públicos dos entes autônomos que recebem tais recursos, principalmente aqueles decorrentes de arrecadação tributária (Meier \& Otoole Junior, 2002). Estudos anteriores sobre o tema já indicaram que, ao menos em tese, o acréscimo das despesas públicas poderia acontecer em ritmo 
superior ao valor arrecadado oriundo de repasses. Tal fenômeno é conhecido na literatura como efeito flypaper. Consiste na tendência de que transferências de um nível do governo para outro fiquem com o destinatário, sendo usado para prestação de serviços, e não são repassadas aos contribuintes, na forma de redução de impostos. Ele ocorre quando um dólar decorrente de uma transferência exógena leva a uma despesa pública significativamente maior do que um dólar na renda dos cidadãos: o dinheiro fica onde ele bate (Hines \& Thaler, 1995).

Nesta perspectiva, esta pesquisa tem por objetivo geral avaliar o desempenho organizacional dos municípios brasileiros, verificando a existência do efeito flypaper. Com sua realização, é possível verificar, por meio do efeito flypaper, se o crescimento dos gastos públicos nos municípios brasileiros é imputável aos repasses intergovernamentais. Elucidada essa breve contextualização, tem-se o seguinte problema de pesquisa: "O comportamento dos gastos públicos no âmbito dos municípios brasileiros condiz com o efeito flypaper"?

A justificativa da pesquisa reside na verificação da existência desse fenômeno (efeito flypaper), que não foi suficientemente explorado cientificamente, bem como na análise de suas causas. No caso afirmativo de sua existência, as causas de aumento dos gastos públicos podem ser endereçadas pela análise gerencial. Assim, contribuem para que a República Federativa do Brasil estabeleça critérios técnicos e razoáveis para os repasses intergovernamentais.

O trabalho está estruturado em cinco tópicos. Este corresponde ao problema de pesquisa e ao objetivo a ser buscado. O próximo refere-se à revisão de temas específicos de finanças públicas, com vistas à compreensão do efeito flypaper. O terceiro tópico traz breve abordagem da metodologia adotada e da descrição dos dados. Em seguida, tem-se os resultados apresentados e as discussões pertinentes. Por fim, a quinta seção trata das conclusões e sugestões para novas pesquisas na área.

\section{REVISÃO DE LITERATURA}

O federalismo é um sistema de governo em que o poder é dividido entre o governo central e os regionais, sendo meio termo entre governo unitário (concentrado em uma única entidade política) e confederação (cujo poder central é fraco ou mesmo nulo). Por meio do pacto federativo, entes políticos autônomos se organizam e se relacionam entre si, de modo a formar um todo, uma única unidade também autônoma. $\mathrm{O}$ federalismo se traduz na própria forma de exercício do poder estatal e na influência que os entes subnacionais podem exercer em cada um de seus territórios. Isso se reflete nas mais variadas formas de estabelecimento de poderes, como por exemplo, as províncias, distritos, estados, munícipios e tantas outras observadas ao longo da história. No caso brasileiro, pode-se constatar a junção dos Estados, que resultou na unidade central denominada União. Nesse relacionamento entre federações, a descentralização fiscal (também denominada de federalismo fiscal) passou a ganhar cada vez mais importância no estudo das finanças públicas (Coser, 2008).

Em simetria à concepção original de federalismo, a descentralização fiscal assume a faceta da própria razão de ser do Estado, no tocante a duas importantes alçadas assumidas pelos entes políticos autônomos: 1) o poder de arrecadação de receitas, mediante exercício da autoridade coercitiva do Estado, afirmando sua superioridade perante o particular, ou até mesmo por intermédio de atividades empresariais com o intuito de obter renda, em que o Estado e particular se encontram em pé de igualdade; e 2) o poder de despender recursos, de maneira a prover bens e serviços públicos para a sociedade (Mendes, 2013).

Dentro desse escopo, tem-se a obtenção de receitas públicas, a criação de crédito público (endividamento), a gestão do orçamento governamental e o dispêndio de despesas públicas (Jund, 2008). Assim, a captação, a geração e o gasto de recursos objetivam prover os serviços estatais e atender as demandas coletivas. A descentralização fiscal não deixa de retratar a forma de interação dos mercados de bens privados para regular a oferta e demanda de bens públicos. Os governos locais assumem o papel de provedores, com atuação bem próxima à verificada nas firmas inseridas no mercado de bens privados. Já as famílias (consumidores) estimulam a curva de demanda, em que 
optam por pagar o "preço" (na forma de tributos) para usufruir dos bens públicos de sua preferência (Biderman \& Arvate, 2004; Zuccolotto \& Teixeira, 2017).

Ressalta-se a competição entre governos locais como aspecto positivo para implantação do federalismo fiscal nas nações, denominado de concorrência horizontal. A mobilidade da sociedade poderia fazer com que fossem reveladas suas preferências por bens públicos, de modo a facilitar sua provisão em nível ótimo. Assim, a medida incentivaria os governos a ofertarem cestas de bens públicos cada vez melhores à população, cabendo aos indivíduos decidirem os próprios locais de residência, tendo por ônus o financiamento da estrutura governamental escolhida mediante pagamento de tributos. Por outra via, traz como fator limitador a presença de externalidades e até mesmo a própria mobilidade entre localidades (Tiebout, 1956).

Oates (1972) ressalta a importância, tanto do governo central, quanto dos governos locais, no processo de maximização da eficiência do setor público. Sob essa concepção, o federalismo fiscal tenderia a compatibilizar as competências e características inerentes de cada um dos entes políticos. Tal compatibilização geraria uma sinergia, de tal forma que a concorrência entre os diversos níveis de governo tornaria a interação vantajosa, por intermédio de ações cooperativas horizontais (entre governos locais) e verticais (entre governo central e subnacional). Pode-se citar a repartição de funções entre os demais níveis políticos e a maior participação e fiscalização nas decisões tomadas. Por também considerar os benefícios da interatividade com o governo central, as ponderações de Oates (1972) conflitam com aquelas apresentadas por Tiebout (1956), pois a concorrência horizontal não possui capacidade de elevar a eficiência econômica por si só.

Gordon (1983) trata do impacto das externalidades em economias descentralizadas, até então consideradas como fator limitador nos estudos de Tiebout (1956). Para o autor, a intensidade dos efeitos externos (sejam eles positivos ou negativos) seria tanto maior quanto fosse o nível de descentralização observado no setor público. Isto é, a complexidade do sistema federativo oportuniza o aparecimento de falhas de mercado dessa natureza, o que poderia incitar a perda de eficiência econômica. Entre as externalidades, destacam-se a exportação de tributos a não residentes, os freeriders (caronas), a regressividade tributária e a guerra fiscal (Biderman \& Arvate, 2004).

Apesar de existirem restrições quanto ao alcance dessa eficiência, compreender o alcance das externalidades não deixa de ser uma maneira eficaz para reduzi-las, permitindo normatizar um modelo de pacto federativo consistente. Dessa forma, o federalismo fiscal ainda é considerado importante técnica de atuação do Estado. Incentiva o aumento de autonomia dos governos nas decisões fiscais e, por conseguinte, no aumento da parcela destinada ao orçamento dos entes federados (Guedes \& Gasparini, 2007).

No campo de estudo das finanças públicas, existem correntes doutrinárias diversas que procuram explicar os motivos que levam as despesas públicas crescerem ao longo do tempo. Adolf Wagner formulou a teoria que ficou conhecida como Lei do Crescimento Incessante das Atividades Estatais, ou "Lei de Wagner". Segundo a concepção, à medida que o nível de renda dos países industrializados cresce, os dispêndios sempre crescem a taxas mais elevadas, sendo a elasticidaderenda superior à unidade nesses casos. Em sentido oposto à visão de Wagner, economistas atribuem o crescimento das despesas públicas à oferta de serviços públicos mediante tributação, e não à demanda. Os dispêndios tenderiam a crescer em situações de crise, momento em que a sociedade não apresentaria maior resistência à criação ou aumento de tributos. Tal fenômeno é denominado de efeito translação, ou efeito do limite tributário (Peacock \& Wiseman, 1970). O arcabouço legal e institucional vigente no Brasil contempla a repartição de competências e de receitas, também denotado de sistema de equalização tributária. Nesse contexto, tem-se o financiamento fiscal realizado pelos governos superiores (União e Estados) aos inferiores (Municípios) e os subsequentes efeitos dos repasses nos gastos públicos municipais.

As primeiras evidências a respeito da ocorrência do efeito flypaper foram elucidadas por Courant, Gramlich e Rubinfeld (1979) e Oates (1979), os quais afirmam que está relacionado à preferência de burocratas e políticos evitarem a redução de impostos quando o governo recebe fundos 
de repartição de receitas, do que a elevação de tributos quando algum evento exógeno resulta em aumento de renda da comunidade. Sendo assim, a origem do termo flypaper effect remete-se ao fato de que o "dinheiro fica onde bate", em referência às moscas que pousam em papéis papa-moscas. Isto é, o recurso captado pela comunidade tem por origem o próprio setor público (governo responsável pela transferência), e este recurso fica ali mantido, não transitando ao setor privado. Ambas as linhas de conclusão, seja a de Courant et al. (1979) e Oates (1979), ou a de Winer (1983) e Logan (1986), apontam que as transferências ou subvenções reduzem o custo marginal percebido do bem público, possibilitando o aumento da despesa pública (Biderman \& Arvate; 2004; Araújo \& Siqueira, 2016).

Oates (1988), mesmo afirmando que o efeito flypaper era uma das possibilidades de ilusão fiscal, já indicava que não seria necessário qualquer tipo de ilusão fiscal para gerar o efeito flypaper. Romer e Rosenthal (1979), por exemplo, mostram que nos locais em que é estabelecido um modelo de controle orçamentário (agenda control model), há maior possibilidade de gastos públicos excessivos. Os responsáveis pelo orçamento se aproveitariam de alternativas orçamentárias pouco atrativas (maiores gastos públicos), sendo que a mais atrativa do ponto de vista do eleitorado ainda poderia ser considerada uma reversão da situação prejudicial da menos atrativa, o que causaria uma sensação de reversão do "pior orçamento". Assim, Oates (1988) defende a necessidade de mais evidências empíricas do efeito flypaper.

O efeito flypaper é então o alto grau de sensibilidade (elasticidade) dos gastos públicos do ente federado, em virtude do montante arrecadado decorrente de transferências advindas de outros governos. A hipótese ilustra que quanto maior é a quantidade de recursos repassados por outros entes federativos, o gasto público do ente recebedor seria proporcionalmente maior à renda obtida. Sendo assim, o efeito flypaper pode gerar distorções no sistema de repartição de receitas, bem como o descompasso na execução orçamentária e financeira do ente federativo, de modo que as despesas superem as receitas, ampliando os gastos governamentais. Para manutenção do equilíbrio fiscal, entes tomam empréstimos e elevam a dívida pública, comprometendo sua sustentabilidade a longo prazo. Sob um cenário em que a premissa do efeito flypaper é verdadeira, há maior propensão para que os entes beneficiários aumentem suas despesas em resposta aos subsídios lump-sum, comparativamente aos aumentos percebidos pelo setor privado (Rios \& Costa, 2005).

O fenômeno simboliza, portanto, a tendência de que transferências intergovernamentais recebidas por governos subnacionais ocasionem elevações nos gastos públicos, ao invés de serem redistribuídas ao setor privado mediante redução de impostos. Cientistas políticos e economistas defendem que o efeito flypaper faz com que ajudas intergovernamentais estimulem a execução das despesas públicas em ritmo superior aos comparáveis com rendimentos fundamentados sob o modelo de certeza de ilusão fiscal. No entanto, quando posta em prática, a descentralização fiscal vem geralmente acompanhada de descontrole nos gastos dos governos locais, o que pressiona as finanças públicas dos governos locais e centrais, prejudicando a política econômica do país (Wyckoff, 1988; Turnbull, 1998).

Há de se destacar que, em regra, a demanda por gastos públicos reflete a abordagem do teorema do eleitor mediano. O princípio aduz que a massa de políticos deseja majorar as chances de serem eleitos. Para alcançar esse objetivo, as escolhas que envolvem a provisão de bens e serviços públicos à sociedade satisfazem as necessidades do eleitor mediano, o que significa que, dentro de um sistema de eleição majoritário, devem ser contentadas as preferências do eleitorado relevante, aqui entendido como aquele responsável por determinar a base de governantes institucionalizada. Assim, as ações voltadas à satisfação das demandas da maioria convergem para a maximização de sua utilidade (Barcelos, 2007).

Existem modelos teóricos inseridos no contexto do efeito flypaper que explicam o fenômeno da expansão dos gastos públicos ao longo do tempo. Entre as principais concepções, destacam-se os modelos de maximização do orçamento (budget-maximizing model, também denotado de modelo burocrático) e de ilusão fiscal. Em um primeiro momento, os estudos em torno do modelo burocrático se reportam aos trabalhos de Niskanen (1971). A definição leva a efeito a assimetria de informações 
entre a corrente governista e o eleitor mediano. Os burocratas, por se encontrarem estabelecidos no poder em mandato definido, não possuem incentivos suficientes para revelar o nível de financiamento da máquina pública aos cidadãos. Assim, a transparência e fidedignidade das informações disponibilizadas se vê prejudicada, posto que os burocratas se utilizam de distorções para manter margem orçamentária mais elevada, para executar despesas que melhor convém aos interesses do governo instituído.

Com isso, o eleitor mediano desconhece a real restrição orçamentária do governo, principalmente em relação a programas de seu interesse, repercutindo em gastos públicos maiores em áreas que não necessariamente beneficiam a sociedade. Isto é, o administrador burocrata manipula a peça orçamentária, reduz gastos com os programas populares e aloca os recursos da maneira que melhor convém a seus interesses, sejam eles pessoais ou políticos (Correia, 2014).

Dessa forma, os administradores do setor público, na condição de maximizadores de orçamento, não têm nenhum incentivo para corrigir as percepções dos eleitores em relação aos impostos cobrados. Pelo contrário, suportariam gastos públicos maiores do que deveriam se estivessem sob ambiente de informação perfeita, o que caracteriza o efeito flypaper, muito embora os eleitores não estejam completamente cientes da ocorrência de repasses intergovernamentais (Turnbull, 1992).

Já a Teoria da Ilusão Fiscal foi inicialmente desenvolvida por Puviani (1903). Diz respeito à capacidade dos governos em manipular a própria gestão fiscal, criando "ilusão" de que não possui recursos quando de fato possui, e que está gastando quando na verdade não está. Essa postura permite que custos sejam ocultados e benefícios de programas, desejados pela cúpula governista, sejam majorados. O resultado da manipulação fiscal distorce as percepções do eleitor mediano, prejudicado em um ambiente de informação imperfeita, que lhe impede de demandar bens e serviços públicos que seriam, de fato, de seu interesse (Araújo \& Siqueira, 2016).

A ilusão fiscal muitas vezes se confunde com o modelo burocrático. Isso porque os agentes políticos aproveitam as falhas de percepção do eleitorado sobre os custos dos bens públicos para maximizar o orçamento. Como os repasses efetivados aos entes subnacionais reduzem o custo médio dos bens públicos, o fato pode causar aos eleitores a falsa impressão de que os custos médios e marginais são equivalentes (Rios \& Costa, 2005). Buchanan (1967) registra que o comportamento dos indivíduos frente à ilusão fiscal não é necessariamente irracional. Na verdade, a presença de ilusão fiscal não causa interferências nas decisões dos particulares, cujos alicerces são a coerência e a consistência, seja em decorrência do ambiente de informação imperfeita ou não. Mas, o contribuinte não tem condições de atingir discernimento suficiente sobre a existência de ilusão fiscal, a ponto de se relacionar com os burocratas e exigir que suas demandas sejam satisfeitas.

Nessa ausência de compreensão, os governos possuem total controle das informações, divulgando aquelas que lhe são favoráveis. Assim, as transferências intergovernamentais criam a ilusão de que os bens e serviços providos pelos governos locais são financiados por não residentes, facilitando a expansão do gasto público. Economistas elucidam, ao menos, três fontes de ilusão fiscal: 1) a complexidade do sistema tributário; 2) a visibilidade dos tributos; e 3) o impacto gerado pelos repasses intergovernamentais no financiamento dos gastos públicos. Este último representa a própria aplicabilidade do efeito flypaper (Araújo \& Siqueira, 2016; Zuccolotto \&Teixeira, 2017).

O efeito flypaper sob a ótica da ilusão fiscal reproduz uma visão míope do eleitor mediano sobre as decisões alocativas e distributivas do governo. Vale lembrar que, sob a teoria do eleitor mediano, o aumento na arrecadação do governo local, advindo do sistema de transferências, seria acompanhado de aumento proporcional nas despesas públicas do ente federativo, o que, de certa forma, conflita com os gastos crescentes observados no efeito flypaper. Logo, os burocratas ofertam cestas de bens e serviços públicos que, apesar de serem mesmo demandados pelo eleitorado, não coincidem com as exigências e desejos de um ambiente sem assimetria de informação (Nojosa \& Linhares, 2015). 
Por fim, existem casos em que é possível conciliar o efeito flypaper com a hipótese do eleitor mediano. Por exemplo, quando os tributos não são cobrados eficientemente pelos governos locais. Portanto, quando o montante oriundo de repasses intergovernamentais não é suficiente ante a baixa arrecadação de receita, os governos seriam forçados a suprir a demanda reprimida da sociedade, de maneira a elevar seu bem-estar. Isso viabiliza e estimula ainda mais para que os gastos públicos sejam proporcionalmente superiores às receitas de transferências, só que no contexto de maximização de utilidade do contribuinte (Biderman \& Arvate, 2004). Logo, as teorias base para o presente estudo são a Teoria do Eleitor Mediano, as teorias já citadas do Federalismo Fiscal e a Teoria da Ilusão Fiscal, que sustentam a existência conceitual do efeito flypaper. Pesquisas anteriores sobre flypaper evidenciaram a existência do fenômeno, tanto no nível municipal, quanto no nível estadual.

\section{METODOLOGIA}

Com a finalidade de obter evidências do efeito flypaper nos municípios brasileiros, o presente estudo teve por base a abordagem estatística de modelo em dados em painel. Entre as justificativas para adoção desse método, tem-se a própria forma de organização dos dados, o contínuo período em exame e a grande quantidade de elementos a serem observados. Foram coletados dados referentes a 5.570 municípios entre 2005 e 2018, o que corresponde ao total de 61.666 observações. O modelo utilizado na presente pesquisa baseia-se em Araújo (2014) e Araújo e Siqueira (2016), construído a partir teoria da escolha pública, desenvolvida por Borcherding e Deacon (1972) e Bergstrom e Goodman (1973). Assim, utilizou-se estratégia similar à adotada em vários trabalhos já realizados sobre o tema, a exemplo das discussões levantadas por Correia (2014), Rios e Costa (2005), Cossio e Carvalho (2001), entre outros. Cabe registrar que foi utilizado como ferramenta de suporte e referência no processo de análise dos dados e da escolha do modelo econométrico o software estatístico Stata - Data Analysis and Statistical Software, versão 15 (StataCorp, 2015).

O modelo geral de análise de dados em painel pode ser descrito na forma de uma equação de regressão linear múltipla:

$$
Y_{i t}=\beta_{0 i t}+\beta_{1 i t} X_{1 i t}+\cdots+\beta_{k i t} X_{k i t}+\varepsilon_{i t}
$$

Sendo que $i$ é o número de indivíduos da amostra, $t$ é o período de tempo, $\beta_{0}$ é o parâmetro de intercepto, $\beta_{k}$ é o coeficiente angular referente a $k$-ésima variável independente/explicativa $X$ e $\varepsilon$ é o termo de erro estocástico. Todavia, deve-se estabelecer premissas para que a equação (1) se torne aplicável. Para a abordagem de dados em painel, a literatura enfatiza os modelos regressivos de efeitos fixos e aleatórios como aqueles de maior adequabilidade para explicar o relacionamento entre as variáveis. Tal modelo é assim representado:

$$
Y_{i t}=\alpha_{i}+\beta_{1 i t} X_{1 i t}+\cdots+\beta_{k i t} X_{k i t}+\varepsilon_{i t}
$$

Sendo que $\alpha_{i}$ representa o intercepto específico a ser estimado para cada indivíduo. $\mathrm{O}$ estimador de efeitos fixos tem por base os desvios das variáveis explicativas em relação aos valores médios, eliminando o efeito da heterogeneidade. Esse processo é obtido por intermédio do método dos Mínimos Quadrados Ordinários (Ordinary Least Squares - OLS). A formulação com efeitos fixos surge como melhor opção para modelagem de dados em painel quando o intercepto $\alpha_{i}$ possui correlação com variáveis explicativas em qualquer tempo. (Duarte, Lamounier, \& Takamatsu, 2007). Já no modelo com efeitos aleatórios, também se presume que os indivíduos apresentam heterogeneidade, só que o efeito que a diferenciação causa às variáveis explicativas é absorvido pelo componente de erro, e não diretamente pelo intercepto:

$$
Y_{i t}=\alpha_{i}+\beta_{1 i t} X_{1 i t}+\cdots+\beta_{k i t} X_{k i t}+\omega_{i t} ; \text { onde } \omega_{i t}=\eta_{i}+\varepsilon_{i t}
$$


O estimador de efeito aleatório é obtido mediante uso dos Mínimos Quadrados Generalizados - MQG (Generalized Least Squares - GLS), por intermédio da aplicação do método de Gauss-Markov. Isso por causa da propriedade da autocorrelação, indicando não ser conveniente a aplicação do MQO. Conhecidos os estimadores dos efeitos fixos e aleatórios, a execução do teste de especificação de Hausman permite indicar qual deles é predominante. Trata-se de teste estatístico que permite avaliar quais dos modelos econométricos citados apresentam maior consistência e confiabilidade, para fins de escolha da base de análise. O teste de Hausman possui distribuição $\chi^{2}$ assintótica, cuja hipótese nula é de que não há distinção significativa entre os estimadores dos modelos fixo e aleatório. Dessa forma, caso o teste indique que a hipótese nula deva ser rejeitada, é preferível adotar o modelo de efeitos fixos ao invés do modelo aleatório. Foram utilizadas técnicas próprias de estatística descritiva como forma de se obter um breve diagnóstico das variáveis. Em seguida, foram feitos testes econométricos preliminares, com o objetivo de verificar a adequação dos pressupostos dos modelos de regressão, a exemplo da multicolinearidade, autocorrelação e heterocedasticidade. Enfim, procedeu-se análises de significância estatística do modelo determinado pelo teste de especificação de Hausman, sendo que as principais serão descritas a seguir. Vale lembrar que o nível de significância determinado para esta pesquisa é de 5\% (Gujarati \& Porter, 2011).

Para atingir os objetivos estabelecidos neste artigo, o efeito flypaper (observação empírica de que transferências lump sum para os municípios a partir dos níveis mais altos do governo ficam onde elas batem), como uma anomalia na literatura das finanças públicas locais. Assim, as transferências do nível federal tornam os municípios ineficientes em suas próprias arrecadações, o que já foi verificado também por outros (Costa, 2013; Schettini, 2012; Severo Filho, 2012).

Econometricamente, se o coeficiente das transferências lump sum for maior que o do PIB (ou renda), está-se diante do efeito flypaper, que representa o efeito expansivo das transferências sobre os gastos públicos. Nesta ótica, foram definidas as variáveis subsequentes para confirmar o efeito flypaper: despesa corrente, população, repasses intergovernamentais recebidos, Produto Interno Bruto (PIB) e receita tributária. Ao trazê-las para o formato da equação (1), tem-se que:

$$
\text { lnDespesa }_{i t}=\alpha_{i}+\beta_{1} \text { lnPop }_{i t}+\beta_{2} \text { lnRepasses }_{i t}+\beta_{3} \text { lnPIB } \text { Re }_{i t}+\beta_{4} \text { lnReceita }_{i t}+\varepsilon_{i t}
$$

Sendo lnDespesa $a_{i t}$ o logaritmo neperiano do total das despesas correntes empenhadas do $i$ ésimo município no ano $\mathrm{t}$; $\operatorname{lnPop}_{i t}$ o logaritmo neperiano da população residente no i-ésimo município no ano $\mathrm{t}$; lnRepasses ln $_{i t} \mathrm{o}$ logaritmo neperiano das transferências correntes recebidas pelo i-ésimo município no ano t; $\operatorname{lnPIB} B_{i t}$ o logaritmo neperiano do Produto Interno Bruto do i-ésimo município no ano $\mathrm{t}$; $\operatorname{lnReceita}_{i t} \mathrm{o}$ logaritmo neperiano da receita tributária arrecadada pelo $i$-ésimo município no ano t; e $\varepsilon_{i t}$ o componente de erro. Registra-se que é prática comum o uso do coeficiente de logaritmo natural junto às variáveis explicativas, posto que sua utilização traz estímulos à linearização e possibilita realizar estimativas com valores nominais e com elasticidades.

O motivo do uso das variáveis é inicialmente em função da essência do efeito flypaper, que consiste na verificação da elasticidade gasto/repasse, que exige, desde então essas, duas variáveis, representadas pela despesa corrente e pelos repasses. Além disso, é necessário verificar a resposta desse gasto frente ao aumento da renda da população, motivo pelo qual o PIB é também uma das variáveis. Por fim, em função da diversidade do tamanho dos 5.570 municípios brasileiros, o modelo considera a variável população como relevante na consideração desses impactos. Por fim, os estudos anteriores também consideram essas variáveis, afinal, são essenciais para a verificação da existência do efeito, conforme o Quadro 1.

As variáveis de execução orçamentária foram extraídas de aplicativos e sistemas web de banco de dados da Secretaria do Tesouro Nacional (STN), denominados Finanças do Brasil - Dados Contábeis dos Municípios (Finbra), e Sistema de Informações Contábeis e Fiscais do Setor Público Brasileiro (Siconfi). Tais dados contemplam os registros contábeis orçamentários relativos aos balanços consolidados municipais, cujas informações são fornecidas pelos próprios municípios à 
STN. Já os dados de população residente e dos PIBs municipais foram consultados junto à página eletrônica do Instituto Brasileiro de Geografia e Estatística (IBGE).

A receita tributária segue as classificações orçamentárias e contábeis definidas pela STN em cada exercício financeiro, sendo a arrecadação basicamente composta por impostos, taxas e contribuições de melhoria. Os repasses intergovernamentais tratam de valores recebidos pelos municípios a título de transferências correntes, a exemplo das cotas-parte dos Fundos de Participação dos Municípios (FPM) e de impostos, como o Imposto sobre Circulação de Mercadorias e Serviços (ICMS) e o Imposto sobre a Propriedade de Veículos Automotores (IPVA).

Para a variável despesa corrente, foram consideradas as despesas empenhadas, por espelharem adequadamente o efeito dos restos a pagar não processados inscritos ao final de cada exercício financeiro. Integram o grupo corrente as despesas com pessoal, juros e encargos da dívida e outras despesas correntes. Foram enfrentadas limitações no levantamento dos dados, tendo em conta que as bases de dados do Finbra e do Siconfi dependem de informações repassadas pelos municípios à STN, não abrangendo a totalidade destes. Além disso, o IBGE não disponibilizou dados da população residente para todos os períodos. Nessa falta, utilizou-se os dados divulgados pelo Finbra e pelo Siconfi para complementação. Apesar disso, as limitações não se mostraram relevantes a ponto de prejudicar a análise por falta de dados, dada a representatividade da amostra coletada. A Tabela 1 traz um resumo das variáveis explicativas e os respectivos efeitos esperados sobre os gastos públicos.

Tabela 1 - Descrição das variáveis explicativas

\begin{tabular}{|c|c|c|}
\hline Variável & Expectativas & \multicolumn{1}{c|}{ Referências } \\
\hline População & Positivo & $\begin{array}{l}\text { Araújo (2014), Araújo e Siqueira (2016), Costa e Castelar (2015), Araújo e Siqueira } \\
\text { (2016), Vegh e Vuletin (2016), Gadelha, Oliveira, Botelho e Teixeira (2017), Ferreira, } \\
\text { Serrano e Revelli (2019), Mattos, Cardim e Politi (2018), Pansani, Serrano e Ferreira } \\
(2020) .\end{array}$ \\
\hline Transferências & Positivo & $\begin{array}{l}\text { Araújo (2014), Araújo e Siqueira (2016), Costa e Castelar (2015), Araújo e Siqueira } \\
\text { (2016), Vegh e Vuletin (2016), Gadelha et al. (2017), Ferreira et al. (2019), Freitas, } \\
\text { Pereira, Lúcio e Gomes (2019), Mattos et al. (2018), Pansani et al. (2020). }\end{array}$ \\
\hline PIB & Negativo & $\begin{array}{l}\text { Araújo (2014), Araújo e Siqueira (2016), Costa e Castelar (2015), Araújo e Siqueira } \\
\text { (2016), Vegh e Vuletin (2016), Gadelha et al. (2017), Ferreira et al. (2019), Freitas et } \\
\text { al. (2019), Mattos et al. (2018), Pansani et al. (2020). }\end{array}$ \\
\hline Receita & Positivo & $\begin{array}{l}\text { Araújo (2014), Araújo e Siqueira (2016), Costa e Castelar (2015), Araújo e Siqueira } \\
\text { (2016), Gadelha et al. (2017), Freitas et al. (2019). }\end{array}$ \\
\hline
\end{tabular}

Fonte: Elaboração própria.

Espera-se que variações positivas na receita tributária municipal arrecadada promovam maior oferta de bens e serviços públicos à sociedade, repercutindo no aumento dos gastos públicos. Essa expectativa é compatível, inclusive, com o princípio do equilíbrio orçamentário, em que as receitas igualam as despesas.

No mesmo sentido, é esperado que a receita auferida pelos munícipios decorrentes de repasses intergovernamentais também eleve o montante dos dispêndios. Todavia, o atual panorama da administração pública brasileira (situação delicada das finanças públicas municipais, com redução da arrecadação e elevação do contingenciamento de despesas) permite supor que o crescimento dos gastos não seja demasiadamente elástico ao observado pela variável transferências, o que não confirmaria a hipótese do efeito flypaper. Há expectativa de que também haja aumento na demanda e na provisão de bens públicos (ex.: saúde, educação, segurança, entre outros), em virtude do crescimento da população residente. Logo, as variações positivas das populações tendem a gerar efeitos crescentes nos dispêndios públicos.

Ressalta-se que a variação das despesas correntes em função dos aumentos na produção interna não é necessariamente positiva. Sob o ponto de vista macroeconômico, o crescente nível de produção municipal tende a elevar a renda e a formar poupança pública, estimulando as exportações e desencorajando as importações. Detidos de maior capacidade econômica, os governos possuem melhores condições financeiras de realizar investimentos de longo prazo nas mais variadas áreas de 
atuação pública, em detrimento à execução dos gastos correntes. Dessa forma, estabelece-se a hipótese de que a relação entre despesa corrente e PIB é negativa.

\section{APRESENTAÇÃO E ANÁLISE DOS RESULTADOS}

A Tabela 2 sintetiza os cálculos dos principais índices de estatística descritiva. Infere-se dos dados que a média das despesas correntes municipais é superior à média das demais variáveis, em especial os repasses intergovernamentais correntes recebidos (superior em 29,76\% em relação a esta última), o que, a princípio, reforçaria a hipótese de que a elasticidade gasto/repasse seja superior à unidade. A soma das receitas tributárias no período é de aproximadamente $\mathrm{R} \$ 818,6$ bilhões, e das despesas correntes, $\mathrm{R} \$ 3,2$ trilhões. Ressalta-se a baixa representatividade da arrecadação, à medida que compõe apenas $25,2 \%$ do total dos referidos gastos. Nesse sentido, é interessante notar que a média do ritmo de arrecadação de tributos ( $\mathrm{R} \$ 13,3$ milhões) também não consegue acompanhar a média de execução da variável dependente ( $\mathrm{R}$ \$ 52,7 milhões).

Tabela 2 - Estatística descritiva dos municípios brasileiros (valores monetários em reais)

\begin{tabular}{l|ccccc}
\hline \multicolumn{1}{c|}{ Estatística } & Despesa & Pop. & Repasses & PIB & Receita \\
\hline Soma & $3,25 \mathrm{e}+12$ & $2,06 \mathrm{e}+09$ & $2,50 \mathrm{e}+12$ & $3,18 \mathrm{e}+10$ & $8,19 \mathrm{e}+11$ \\
Média & $5.27 \mathrm{e}+07$ & $33.385,5$ & $4,06 \mathrm{e}+07$ & $516.164,7$ & $1,33 \mathrm{e}+07$ \\
Mediana & $1,33 \mathrm{e}+07$ & $10.516,5$ & $1,45 \mathrm{e}+07$ & $56.659,96$ & $642.928,6$ \\
Variância & $2,34 \mathrm{e}+17$ & $4,12 \mathrm{e}+10$ & $4,42 \mathrm{e}+16$ & $3,88 \mathrm{e}+13$ & $6,45 \mathrm{e}+16$ \\
Desvio Padrão & $4,84 \mathrm{e}+08$ & $202.984,6$ & $2,10 \mathrm{e}+08$ & 6.228 .062 & $2,54 \mathrm{e}+08$ \\
CV & 9,180154 & 6,080025 & 5,174299 & 12,06604 & 19,12908 \\
Assimetria & 48,3755 & 38,00453 & 39,05494 & 55,90809 & 53,9817 \\
Curtose & 2984,107 & 1893,445 & 2170,959 & 3967,572 & 3489,868 \\
\hline
\end{tabular}

Fonte: Elaboração própria, a partir dos dados obtidos na pesquisa.

Aferiu-se uma base média de receita tributária de $\mathrm{R} \$ 13,3$ milhões que, relacionado com a média populacional de 33,4 mil indivíduos, alcança um montante médio superior a $R \$ 397$ reais de impostos pagos por contribuinte. Essa média populacional também indica uma proporção razoavelmente capaz de estimular a geração de renda (faixa média de $\mathrm{R} \$ 516$ mil).

Figura 1 - Correlação entre despesas correntes e transferências correntes

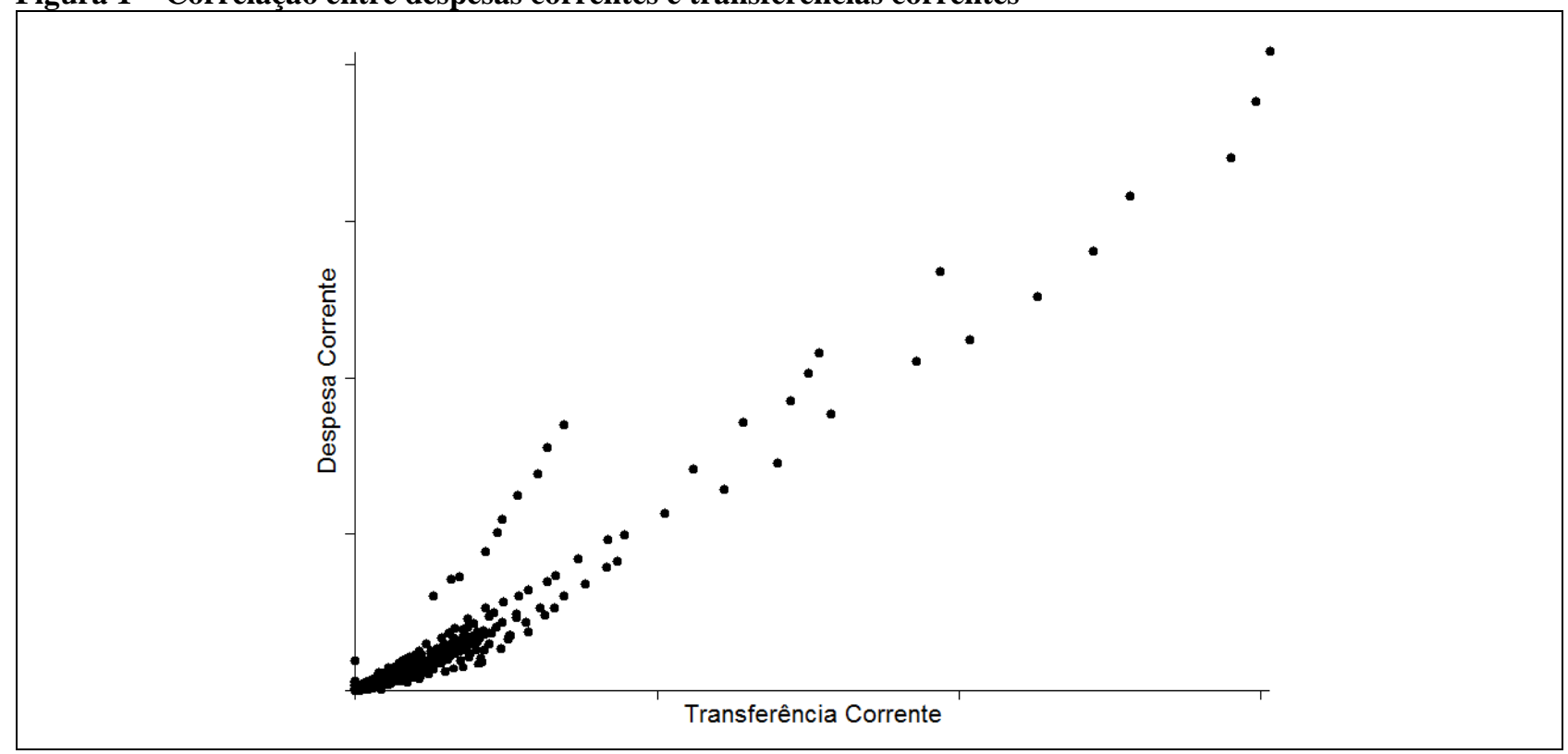

Fonte: Elaboração própria, a partir dos dados obtidos na pesquisa entre 2005 e 2018. 
Os índices de assimetria indicam que a distribuição das variáveis é positiva (assimétrica à direita), dado que as médias são superiores às medianas. Por outro lado, os Coeficientes de Variação $(\mathrm{CV})$, que indicam a relação desvio padrão/média, se mostraram elevados, o que reduz a precisão na análise comparativa das variáveis. Ao verificar a correlação das variáveis despesa corrente e repasses mediante o coeficiente de Pearson, chegou-se ao índice de 0,96 , o que traduz uma forte correlação entre elas. O gráfico a seguir (Figura 1) elucida essa correlação.

Vale lembrar que esta alta correlação não significa que as alterações ocorridas nas transferências intergovernamentais provocam necessariamente variações em ritmo superior nas despesas. Além disso, o conjunto de variáveis como um todo apresentou elevado desvio padrão, o que ainda deixa em aberto a possibilidade de a relação de causa e efeito entre gastos e repasses condizer com o efeito flypaper. Em sequência, são expostos os resultados dos testes preliminares de regressão linear múltipla, com o intuito de confirmar as expectativas em torno das variáveis explicativas e os pressupostos dos modelos de regressão.

Tabela 3 - Resultados dos testes de regressão linear múltipla $(\alpha=5 \%)$

\begin{tabular}{|c|c|c|c|c|c|c|c|c|}
\hline \multicolumn{5}{|c|}{ OLS Simples } & \multicolumn{4}{|c|}{ OLS Robusto } \\
\hline Var. & Coef. & Erro & $\mathbf{T}$ & $\mathbf{P}$ & Coef. & Erro robusto & $\mathbf{T}$ & $\mathbf{p}$ \\
\hline Pop. & 0,2213947 & 0,0030989 & 71,44 & 0,00 & 0,2213947 & 0,025574 & 8,66 & 0,00 \\
\hline Repasses & 0,7872038 & 0,001927 & 408,52 & 0,00 & 0,7872038 & 0,0162896 & 48,33 & 0,00 \\
\hline PIB & $-0,0125986$ & 0,000487 & $-25,87$ & 0,00 & $-0,0125986$ & 0,0012414 & $-10,15$ & 0,00 \\
\hline Receita & 0,0939044 & 0,0022155 & 42,39 & 0,00 & 0,0939044 & 0,0119281 & 7,87 & 0,00 \\
\hline Prob. F & & & & & 0,00 & & & \\
\hline $\mathrm{R}^{2}$ & & & & & 0,9802 & & & \\
\hline
\end{tabular}

Fonte: Elaboração própria, a partir dos dados obtidos na pesquisa.

A princípio, os testes de regressão OLS simples e robusto confirmam os efeitos esperados. Com exceção do PIB, os demais parâmetros estimulam o crescimento dos gastos públicos. Considerando que a probabilidade $\mathrm{F}$ e o $\mathrm{p}$ valor são nulos, e considerando 61.665 graus de liberdade para um $\alpha$ bicaudal $=0,05$, o t calculado para cada variável é superior ao $t$ crítico de 1,96 , o que possibilita rejeitar $H_{0}$ e aceitar $H_{a}\left(\beta_{K} \neq 0\right)$. Logo, a estatística t dos testes preliminares revela que cada uma das variáveis é individualmente significativa para explicar o comportamento da despesa corrente no período em análise.

O $R^{2}$ aponta que as variáveis independentes escolhidas explicam 98,02\% da variação nos gastos, estando bem próximo de um ajustamento perfeito. Isso significa que as variáveis explicativas detêm condições de explicar as oscilações na despesa corrente. No entanto, o alto valor do coeficiente de determinação, conciliado com índices elevados de estatística t, traz indícios de que os modelos regressivos possuem multicolinearidade. Apesar disso, o fenômeno tende a não prejudicar a análise, haja vista que os coeficientes de cada variável confirmam as expectativas e os testes $\mathrm{t}$ não apresentaram falhas.

O próximo passo resume-se à verificação da existência de autocorrelação e heterocedasticidade. Uma possível presença de tais propriedades pode vir prejudicar a confiabilidade das análises, o que demandaria testes complementares para correção dos efeitos. Para a autocorrelação, aplicou-se o teste de Wooldridge para dados em painel, sendo que $H_{0}$ pressupõe-se a ausência de correlação serial, e $H_{a}$, sua constatação. A tabela 4 ilustra o resultado do referido teste.

Tabela 4 - Resultado do teste de Wooldridge para dados em painel $(\alpha=5 \%)$

\begin{tabular}{c|c}
\hline Estatística & Coeficiente \\
\hline F (1, 5605) & 1,609 \\
Probabilidade F & 0,2046 \\
\hline
\end{tabular}

Fonte: Elaboração própria, a partir dos dados obtidos na pesquisa. 
Sendo a probabilidade F de 0,2046 superior ao nível de significância $\alpha=0,05$, aceita-se $H_{0}$ (não há correlação serial), o que dispensa correções adicionais ao modelo nesse sentido. No tocante à heterocedasticidade, optou-se pela realização dos testes de White e de Breusch-Pagan para sua constatação. Para tanto, discute-se as seguintes hipóteses: $H_{0}$ : homocedasticidade; e $H_{a}$ : heterocedasticidade. Os resultados encontram-se na Tabela 5.

Tabela 5 - Resultados dos testes de heterocedasticidade $(\alpha=5 \%)$

\begin{tabular}{lccc} 
& Estatística & Teste de White & Teste de Breusch-Pagan \\
\hline$\chi^{2}$ & & 24500,19 & 91845,89 \\
Probabilidade & 0,00 & 0,00 \\
\hline
\end{tabular}

Fonte: Elaboração própria, a partir dos dados obtidos na pesquisa.

Os testes indicaram a presença de heterocedasticidade do modelo de hipótese, posto que as probabilidades são nulas e menores que o nível de significância, permitindo rejeitar $H_{0}$ e aceitar $H_{a}$. Em posse deste resultado, mostrou-se conveniente adotar como estratégia a realização do teste de especificação de Hausman, para aferir se o modelo de efeito fixo ou o aleatório é o mais indicado e, em fase posterior, proceder aos testes de correção de heterocedasticidade específicos à modelagem definida. Assim, testou-se: $H_{0}$ : indicação do modelo de efeitos aleatórios; e $H_{a}$ : indicação do modelo de efeitos fixos. Os apontamentos a seguir resumem os resultados do teste de Hausman, já com os coeficientes estimados por efeitos fixos e aleatórios.

Tabela 6 - Teste de Hausman, com as estimativas para os modelos de efeitos fixos e aleatórios $(\alpha=5 \%)$

\begin{tabular}{|c|c|c|c|c|c|c|c|c|}
\hline \multicolumn{5}{|c|}{ Efeitos Fixos } & \multicolumn{4}{|c|}{ Efeitos Aleatórios } \\
\hline Var. & Coef. & Erro & $\mathbf{t}$ & $\mathbf{p}$ & Coef. & Erro & $\mathbf{z}$ & $\mathbf{P}$ \\
\hline Pop. & 0,776535 & 0,0055289 & 140,45 & 0,00 & 0,2775898 & 0,003515 & 78.97 & 0,00 \\
\hline Repasses & 0,4056866 & 0,0038033 & 106,67 & 0,00 & 0,7564791 & 0,0021658 & 349.29 & 0,00 \\
\hline PIB &,- 0179846 & 0,0004464 & -40.29 & 0,00 &,- 0134848 & 0,0004772 & -28.26 & 0,00 \\
\hline Receita & 0,2166151 & 0,0036929 & 58,66 & 0,00 & 0,0946654 & 0,0024882 & 38.05 & 0,00 \\
\hline $\mathrm{R}^{2}$ within & & & 0,979 & & $\mathrm{R}^{2}$ within & & & \\
\hline $\mathrm{R}^{2}$ between & & & 0,94 & & $\mathrm{R}^{2}$ between & & & \\
\hline $\mathrm{R}^{2}$ overall & & & 0,96 & & $\mathrm{R}^{2}$ overall & & & \\
\hline $\mathrm{F}$ & & & 4,33 & & Wald $\chi^{2}$ & & 2,83 & \\
\hline Prob. F & & & 0,00 & & Prob. $\chi^{2}$ & & & \\
\hline \multicolumn{9}{|c|}{ Teste de Especificação de Hausman } \\
\hline$\chi^{2}$ & & & & & & & & 47,03 \\
\hline Probabilida & & & & & & & & 0,00 \\
\hline
\end{tabular}

Fonte: Elaboração própria, a partir dos dados obtidos na pesquisa.

O teste de Hausman permitiu concluir que o modelo de maior robustez para a análise de dados em painel nesta pesquisa é a regressão por efeitos fixos, visto que o valor $\chi^{2}$ é altamente significativo para uma probabilidade nula e inferior ao nível de significância definido, a qual permite rejeitar $H_{0}$ e aceitar $H_{a}$.

Tabela 7 - Resultado do teste de Wald de heterocedasticidade grupal para o modelo de efeitos fixos $(\alpha=5 \%)$

\begin{tabular}{l|c}
\hline Estatística & Coeficiente \\
\hline$\chi^{2}$ & $5,8 \mathrm{e}+09$ \\
Probabilidade & 0,00 \\
\hline
\end{tabular}

Fonte: Elaboração própria, a partir dos dados obtidos na pesquisa. 
Com a escolha do modelo de efeitos fixos, e levando a efeito a heterocedasticidade demonstrada na Tabela 5, optou-se por realizar o teste de Wald modificado para verificação de heterocedasticidade grupal, específico para a abordagem de efeitos fixos, com as seguintes hipóteses: $H_{0}$ : homocedasticidade; e $H_{a}$ : heterocedasticidade. A aceitação de $H_{0}$ indica que o modelo de efeitos fixos detém robustez suficiente para analisar a ocorrência do efeito flypaper nos municípios brasileiros. A Tabela 7 traz os resultados do teste de Wald.

Novamente, observou-se no teste de Wald uma estatística $\chi^{2}$ significativa com probabilidade nula, a qual conclui-se pela rejeição de $H_{0}$ e aceitação de $H_{a}$, persistindo a heterocedasticidade. Diante de tal cenário, optou-se por testar a regressão por efeitos fixos com erros-padrão robustos clusterizados, forçando o relaxamento da hipótese de heterocedasticidade. Os resultados encontramse expostos na Tabela 8.

Tabela 8 - Resultado dos estimadores para o modelo de efeito fixo, com correção robusta $(\alpha=5 \%)$ Efeitos Fixos com Erros-Padrão Robustos Clusterizados

\begin{tabular}{lcccc}
\hline Var. & Coef. & Erro robusto & t & P \\
\hline Pop. & 0,776535 & 0,0932294 & 8,33 & 0,00 \\
Repasses & 0,4056866 & 0,051884 & 7,82 & 0,00 \\
PIB &,- 0179846 & 0,0020845 & $-8,63$ & 0,00 \\
Receita & 0,2166151 & 0,027068 & 8,00 & 0,00 \\
\hline $\mathrm{R}^{2}$ within & & & & 0,9791 \\
$\mathrm{R}^{2}$ between & & & & 0,9492 \\
$\mathrm{R}^{2}$ overall & & & 0,9633 \\
Prob. F & & & 0,00 \\
\hline
\end{tabular}

Fonte: Elaboração própria, a partir dos dados obtidos na pesquisa.

De acordo com a Tabela 8, obtém-se as mesmas conclusões em relação aos testes preliminares de regressão OLS simples e robusto, o que justifica a escolha das variáveis explicativas para o método proposto. Tendo em conta os altos valores dos coeficientes de determinação, e que a estatística t de cada variável se encontra bem acima do parâmetro crítico de 1,96 (graus de liberdade $=61.665$ e $\alpha$ bicaudal $=0,05$ ), com probabilidade $\mathrm{F}$ e $\mathrm{p}$ valor nulos e inferiores ao nível de significância, conclui-se pela rejeição de $H_{0}$ e aceitação de $H_{a}$, dando evidências de que as variáveis definidas são estatisticamente significativas, tanto em nível individual, quanto global. Os resultados da abordagem de efeitos fixos permitiram confirmar todas as expectativas traçadas em torno das variáveis independentes. Em relação à população, constatou-se que os gastos correntes acompanham o crescimento do contingente populacional em proporções semelhantes. Os resultados indicam que, para cada $1 \%$ de aumento na população municipal, a despesa cresce $0,77 \%$, coeteris paribus.

Análise semelhante pode ser feita em relação à arrecadação tributária: para cada $\mathrm{R} \$ 1,00$ auferido, a despesa corrente aumenta $\mathrm{R} \$ 0,21$. Observou-se que a receita tributária média é inferior ao gasto corrente médio (vide Tabela 3), o que exigirá uma postura de austeridade fiscal dos municípios no longo prazo. Portanto, sabendo que a despesa corrente tende a crescer em ritmo inferior à arrecadação, no futuro pode ocorrer o fenômeno da capitalização orçamentária, em que o descompasso entre receitas e despesas correntes venha suprir possível insuficiência na arrecadação de receitas de capital. Esse fato pode ainda ocasionar a realização de investimentos públicos com recursos correntes, o que é benéfico à sociedade.

De outro modo, para cada $1 \%$ no aumento na produção, haveria queda de $0,01 \%$ nos gastos públicos. Isso exprime a tendência de que aumentos do PIB viabilizem investimentos em, por exemplo, obras e infraestrutura, do que em despesas correntes. Apesar de comprovar as expectativas, o efeito negativo é ínfimo. Tal resultado pode ser atribuído ao atual e preocupante cenário das finanças públicas municipais, residindo na dificuldade de os entes subnacionais melhorarem os respectivos resultados primários, principalmente no tocante à redução da pressão exercida pelas despesas primárias relativas aos gastos com pessoal. 
Finalmente, em relação aos repasses intergovernamentais, para uma variação de $1 \%$ no aumento dos valores arrecadados pelos municípios a título de transferências correntes, a despesa corrente eleva em aproximadamente $0,4 \%$, para um nível de significância de 5\%, coeteris paribus. Ou seja, os testes econométricos permitiram verificar que a realidade econômica e fiscal dos municípios brasileiros no período em exame não se alinha com os preceitos do efeito flypaper, visto que a elasticidade gasto/repasse não é superior à unidade. Vale lembrar que esta medida de sensibilidade também não foi detectada em nenhum dos testes realizados neste trabalho, como se pode depreender dos resultados elencados pelas Tabelas 3, 6 e 8 .

Os resultados se alinham aos estudos de Costa e Castelar (2015), Correia, Diniz e Costa (2014) e Costa (2013). Porém, não se alinha com os resultados de Araújo (2014), Araújo e Siqueira (2016), Ferreira et al. (2019), Freitas et al. (2019), Mattos et al. (2018), Pansani et al. (2020), Gadelha et al. (2017), Diniz, Lima e Martins (2017), Vegh e Vuletin (2016) e Parmagnani e Rocha (2013). Essa constatação é procedente porque o efeito flypaper é um fenômeno empírico que, baseado nas teorias do federalismo fiscal e do eleitor mediano, pode apresentar resultados diversos a depender do modelo econométrico utilizado, das variáveis, da unidade observada (países, estados, municípios), bem como o período analisado. Portanto, a ciência pode contribuir para solidificar o conceito desse fenômeno e, se for o caso, evoluir para a construção de uma nova teoria.

\section{CONSIDERAÇÕES FINAIS}

Diante ao que foi apresentado, o federalismo fiscal consiste na descentralização de competências para os entes subnacionais, os quais, com autonomia e não soberania, passam a ter competência tributária de determinados tributos, bem como competências para fornecer bens e serviços à comunidade local. Dessa forma, surge o conceito de efeito flypaper, baseado em evidência empírica de que transferências de um nível do governo para outro tendem a "ficar" com o destinatário, sendo utilizadas para prestação de serviços. Nesse sentido, as transferências acabam não sendo repassadas aos contribuintes, na forma de redução de impostos. Consequentemente, transferências resultam em um nível mais alto de prestação de serviços, do que se o pagamento fosse feito diretamente aos indivíduos.

Com base no fenômeno denominado efeito flypaper, que estabelece que o recebimento de transferências fiscais incondicionais e sem contrapartida (lump sum) resulta em aumento das despesas públicas locais proporcionalmente maior do que um aumento equivalente na renda pessoal (Hines \& Thaler, 1995, Hamilton, 1986), a presente pesquisa teve por finalidade verificar a ocorrência do efeito flypaper nos municípios brasileiros. Esse fenômeno poderia explicar a situação econômica e fiscal de um número significativo de entes federativos em questão. Portanto, objetivou-se averiguar qual seria a relação entre os repasses recebidos pelos municípios e os seus respectivos gastos públicos. Para tanto, foram definidas as principais variáveis que traduzem a execução orçamentária e financeira dos municípios (receita tributária, despesa corrente, transferências correntes, população municipal e PIB) e coletados os dados referentes aos exercícios de 2005 a 2018.

Os resultados da aplicação da abordagem de modelo de dados em painel com efeitos fixos revelaram que o flypaper effect não é aplicável no período avaliado. Uma série de fatores podem explicar tais resultados. Por exemplo, a arrecadação de receitas tributárias pode ter sido insuficiente, pois existem municípios que não exercem, de forma plena, a atribuição legal de instituir, prever e arrecadar tributos de sua competência. Dependem da transferência de recursos financeiros de entes superiores para atender as demandas coletivas. Portanto, ao dependerem basicamente de ingressos oriundos de transferências, há tendência natural em retrair os gastos, principalmente em um cenário de baixa arrecadação de tributos. É interessante notar como o efeito flypaper também se relaciona com a questão da eficiência na formação da base tributária municipal.

Além disso, é relevante dizer que, ao tempo em que existem municípios que não cumprem esta competência legal em específico, uma análise sob a ótica da despesa permite inferir que a falta 
de maiores estímulos à execução de gastos correntes em decorrência dos repasses é um indicativo de que os gestores têm receio. Sendo assim, as despesas públicas até podem crescer com o advento das transferências, mas não se espera que isso ocorra em ritmo superior aos ingressos em referência.

Pelo exposto, conclui-se que os objetivos estabelecidos para este trabalho foram atingidos, quais sejam, a caracterização e confirmação da aplicabilidade (ou não) do efeito flypaper nos municípios brasileiros. Para futuras investigações sobre o tema, sugere-se inserir variáveis adicionais referentes à execução orçamentária e financeira dos municípios, a exemplo de receitas e despesas de capital, bem como a ampliação temporal do escopo para fins de análise de dados em painel, o que daria abrangência ainda maior para a apuração.

\section{REFERÊNCIAS}

Araújo, J. M. D. (2014). Um estudo sobre ilusão fiscal no Brasil. Dissertação de mestrado, Universidade Federal de Pernambuco, Pernambuco, Brasil.

Araújo, J. M., \& Siqueira, R. B. (2016). Demanda por gastos públicos locais: evidências dos efeitos de ilusão fiscal no Brasil. Estudos Econômicos, 46(1), 189-219.

Bergstrom, T., \& Goodman, R. (1973). Private Demands for Public Goods. The American Economic Review, 63(3), 280-296.

Biderman, C., \& Arvate, P. R. (2004). Economia do setor público no Brasil. Elsevier. Rio de Janeiro.

Barcelos, C. L. K. (2007). Determinantes da despesa pública local: um estudo empírico dos municípios brasileiros à luz do teorema do eleitor mediano. Dissertação de mestrado, Universidade de Brasília, Brasília, Distrito Federal, Brasil.

Borcherding, T. E., \& Deacon, R. T. (1972). The demand for the services of non-federal governments. American Economic Review, 62(5), 891-901.

Buchanan, J. M. (1967). Public finance in democratic process: Fiscal institutions and individual choice. UNC Press Books. Chapel Hill: University of North Carolina Press.

Correia, J. G. A. (2014). Analisando o comportamento dos gastos públicos nos municípios cearenses: uma análise do efeito Flypaper. Dissertação de mestrado, Universidade Federal do Ceará, Fortaleza, Brasil.

Correia, J. G. A., Diniz, G. I., \& da Costa, R. F. R. (2014). Analisando o comportamento dos gastos públicos nos municípios cearenses. Revista de Políticas Públicas, 18(1), 85-96.

Coser, I. (2008). O conceito de federalismo e a ideia de interesse no Brasil do século XIX. Dados, 51(4), 941-981.

Cossio, F. A. B., \& Carvalho, L. M. D. (2001). Os Efeitos expansivos das transferências intergovernamentais e transbordamentos espaciais de despesas públicas: evidências para os municípios brasileiros: 1996. Pesquisa e Planejamento Econômico, 31(1), 75-124.

Costa, R. F. R. D. (2013). O impacto das transferências constitucionais sobre o comportamento fiscal dos municípios brasileiros. Prêmio Tesouro.

Costa, R. F. R., \& de Melo Castelar, L. I. (2015). O impacto das transferências constitucionais sobre os gastos dos municípios brasileiros. Análise Econômica, 33(64).

Courant, P. N., Gramlich, E. M., \& Rubinfeld, D. L. (1979). The stimulative effects of intergovernmental grants: Or why money sticks where it hits. University of Michigan, Institute of Public Policy Studies, 5-21.

Diniz, J. A., Lima, R. H., \& Martins, V. G. (2017). O efeito flypaper no financiamento da educação fundamental dos municípios paraibanos. Administração Pública e Gestão Social, 9(2), 95-104.

Duarte, P. C., Lamounier, W. M., \& Takamatsu, R. T. (2007). Modelos econométricos para dados em painel: aspectos teóricos e exemplos de aplicação à pesquisa em contabilidade e finanças. In Congresso USP de Iniciação Científica em Contabilidade 4(1), 1-15.

Ferreira, L. O. G., Serrano, A. L. M., \& Revelli, F. (2019). Effects of federal constitutional grants in Brazilian municipalities. Review of Urban \& Regional Development Studies, 31(3), 203-233.

Freitas, T. A., Pereira, R. A. C., Lúcio, F. G. C., \& Gomes, J. W. F. (2019). Uma análise do efeito flypaper e ilusão fiscal para os municípios do nordeste brasileiro. Revista Brasileira de Economia de Empresas, 19(1), 47-60.

Gadelha, S. R. D. B., Oliveira, E. D., Botelho, R., \& Teixeira, A. F. (2017). Austeridade da política fiscal, sustentabilidade da dívida pública e efeito flypaper: Evidências para os governos subnacionais usando 
econometria de dados em painel. Economics and Politics Research Group. Universidade Católica de Brasília, Brasília, Distrito Federal, Brasil.

Gordon, R. H. (1983). An optimal taxation approach to fiscal federalism. The Quarterly Journal of Economics, 98(4), 567-586.

Guedes, K. P., \& Gasparini, C. E. (2007). Descentralização fiscal e tamanho do governo no Brasil. Economia Aplicada, 11(2), 303-323.

Gujarati, D. N, \& Porter, D. C. (2011). Econometria básica (5a ed.). Porto Alegre: AMGH.

Hamilton, J. H. (1986). The flypaper effect and the deadweight loss from taxation. Journal of Urban Economics, 19(2), 148-155.

Hines, J. R., \& Thaler, R. H. (1995). The flypaper effect. Journal of Economic Perspectives, 9(4), 217-226.

Jund, S. (2008). Administração, orçamento e contabilidade pública: teoria e 830 questões. In Administração, orçamento e contabilidade pública: teoria e 830 questões, 885-885.

Logan, R. R. (1986). Fiscal illusion and the grantor government. Journal of Political Economy, 94(6), 13041318.

Mattos, E., Cardim, R., \& Politi, R. (2018). Grants and marginal cost of public funding: Empirical evidence for local governments in Brazil. Revista Brasileira de Economia, 72(4), 479-496.

Meier, K. J., \& O'Toole Jr, L. J. (2002). Public management and organizational performance: The effect of managerial quality. Journal of Policy Analysis and Management: The Journal of the Association for Public Policy Analysis and Management, 21(4), 629-643.

Mendes, S. (2013). Administração financeira e orçamentária-teoria e questões. Rio de Janeiro: Forense.

Niskanen, W. A. (1971). Bureaucracy and representative governments. Chicago: Al-dine and Atherton.

Nojosa, G. M., \& Linhares, F. C. (2015). Variabilidade do efeito flypaper e força política: uma análise para os municípios brasileiros. In Anais do XLIV Encontro Nacional de Economia, 74(1).

Oates, W. E. (1972). Fiscal federalism. Nova York: Harcourt Brace Jovanovich.

Oates, W. E. (1979). Lump-Sum Intergovernmental Grants Have Price Effects. In Fiscal Federalism and Grants-in-Aid, ed. P. Mieszkowski and W. Oakland. Washington, D.C.: The Urban Institute.

Oates, W. E. (1988). On the nature and measurement of fiscal illusion: A survey. Department of Economics, University of Maryland, Sydney, Austrália.

Pansani, D. A., Serrano, A. L. M., \& Ferreira, L. O. G. (2020). Análise de evidências e causas do efeito flypaper e da ilusão fiscal nos estados e municípios brasileiros. Administração Pública e Gestão Social, 12(3).

Parmagnani, F. J. A., \& Rocha, F. F. (2013). Evaluating the impact of SUS transfers on municipalities' health expenditures. University of São Paulo, São Paulo, Brasil.

Peacock, A. T., \& Wiseman, J. (1970). The growth of public expenditure in the United Kingdom. Princeton University Press, Princeton, Nova Jersey, EUA.

Puviani, A. (1903). Teoria della illusione finanziaria [theory of the financial illusion]. ISEDI Istituto Editoriale Internazionale, Milan, Italy.

Rios, M. E., \& da Silva Costa, J. (2005). O efeito flypaper nas transferências para os municípios portugueses. Revista Portuguesa de Estudos Regionais, (8), 85-108.

Romer, T., \& Rosenthal, H. (1979). Bureaucrats Versus Voters: On the Political Economy of Resource Allocation by Direct Democracy. The Quarterly Journal of Economics, 93(4), 563-587.

Schettini, B. P. (2012). Análises da dinâmica orçamentária dos municípios brasileiros: uma aplicação da metodologia VAR com dados empilhados. Economia Aplicada, 16(2), 291-310.

Severo Filho, F. A. A. (2012). Análise do flypaper effect e sua variabilidade nos municípios cearenses. Dissertação de mestrado. Universidade Federal do Ceará, Fortaleza, Brasil.

StataCorp. (2015). Stata 15 base reference manual. College Station, TX: A Stata Press Publication.

Tiebout, C. M. (1956). A pure theory of local expenditures. Journal of Political Economy, 64(5), 416-424.

Turnbull, G. K. (1992). Fiscal illusion, uncertainty, and the flypaper effect. Journal of Public Economics, 48(2), 207-223.

Turnbull, G. K. (1998). The overspending and flypaper effects of fiscal illusion: Theory and empirical evidence. Journal of Urban Economics, 44(1), 1-26.

Vegh, C. A., \& Vuletin, G. (2016). Unsticking the flypaper effect using distortionary taxation (No. w22304). National Bureau of Economic Research. 62(1), 185-237.

Winer, S. L. (1983). Some evidence on the effect of the separation of spending and taxing decisions. Journal of Political Economy, 91(1), 126-140. 
Wyckoff, P. G. (1988). A bureaucratic theory of flypaper effects. Journal of Urban Economics, 23(1), 115129.

Zuccolotto, R., \& Teixeira, M. A. C. (2017). Transparência orçamentária: razões do descompasso entre os estados brasileiros. Organizações \& Sociedade, 24(82), 390-411. 